Case Report

\title{
Asymptomatic Bone Cement Pulmonary Embolism after Vertebroplasty: Case Report and Literature Review
}

\author{
Girolamo Geraci, Giorgio Lo Iacono, Chiara Lo Nigro, Fabio Cannizzaro, \\ Massimo Cajozzo, and Giuseppe Modica
}

Section of General and Thoracic Surgery, University of Palermo, Via Liborio, Giuffrè 5, 90124 Palermo, Italy

Correspondence should be addressed to Girolamo Geraci; ggeraci@unipa.it

Received 18 March 2013; Accepted 15 April 2013

Academic Editors: J. M. Bernal, M. Nikfarjam, and G. Santori

Copyright (c) 2013 Girolamo Geraci et al. This is an open access article distributed under the Creative Commons Attribution License, which permits unrestricted use, distribution, and reproduction in any medium, provided the original work is properly cited.

\begin{abstract}
Introduction. Acrylic cement pulmonary embolism is a potentially serious complication following vertebroplasty. Case Report. A 70-year-old male patient was treated with percutaneous vertebroplasty for osteoporotic nontraumatic vertebral collapse of L5-S1. Asymptomatic pulmonary cement embolism was detected on routine postoperative chest radiogram and the patient was treated with enoxaparin, amoxicillin, and dexamethasone. At the followup CT scan no further migration of any cement material was reported; and the course was uneventful. Discussion. The frequency of local leakage of bone cement is relatively high (about $80-90 \%$ ), moreover, the rate of cement leakage into the perivertebral veins (seen in up to $24 \%$ of vertebral bodies treated) with consequent pulmonary cement embolism varies from 4.6 to $6.8 \%$ (up to $26 \%$ in radiologic studies); the risk of embolism is increased with the liquid consistency of the cement and with the treatment of some malignant lesions. Patients may remain asymptomatic and develop no known long-term sequelae. Conclusions. Our ancedotal case illustrates the need for close monitoring of patients undergoing percutaneous vertebroplasty and emphasizes the importance of prompt and correct diagnosis and treatment, even if actually there is no agreement regarding the therapeutic strategy.
\end{abstract}

\section{Introduction}

Bone cement embolism is a severe and potentially lifethreatening complication of cement (polymethylmethacrylate, PMM) vertebroplasty.

We report a case of asymptomatic PMM pulmonary embolism following a surgical vertebroplasty.

\section{Case Report}

A 70-year-old male patient with a complex medical history of coronary heart disease and hypertension (bicameral pacemaker dependent, left carotid artery stent, and triple aortocoronary bypass) was admitted to our university hospital for osteoporotic nontraumatic vertebral collapse of L5-S1 and spondylotic degeneration of vertebral.

Preoperative serum chemistries and electrocardiogram were normal.
The patient was in a prone position and percutaneous vertebroplasty was performed with a 10-gauge needle, under biplane fluoroscopic control with unilateral transpedicular approach.

Bone cement was classically prepared at $24^{\circ} \mathrm{C}$ by mixing $30 \mathrm{~mL}$ of the PMM powder with $2 \mathrm{~g}$ of sterile barium sulfate powder for opacification and $1 \mathrm{~g}$ of powdered antibiotic, before adding $10 \mathrm{~mL}$ of the liquid monomer; cement injection was monitored on continuous fluoroscopy in the lateral plane with intermittent evaluation in anteroposterior projection to detect early lateral venous leaks. When cement was visualized in the posterior fourth of the vertebral body or beyond the confines of the vertebral body, the procedure was terminated.

Postoperative serum chemistries, arterial blood gas, and cardiac enzymes were normal, and the postoperative course was uneventful.

Pulmonary cement embolism was detected on routine postoperative chest radiograph (Figure 1, cement leakage into 


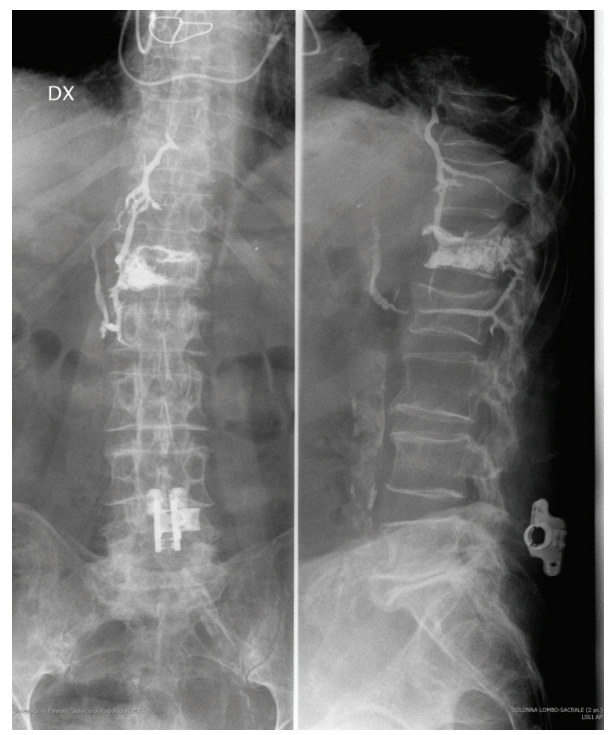

FIGURE 1: Cement leakage into the Batson's paravertebral venous system.

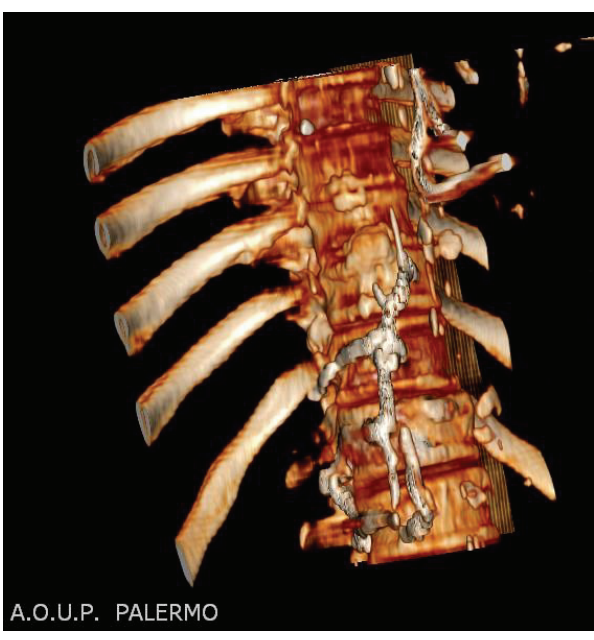

(a)

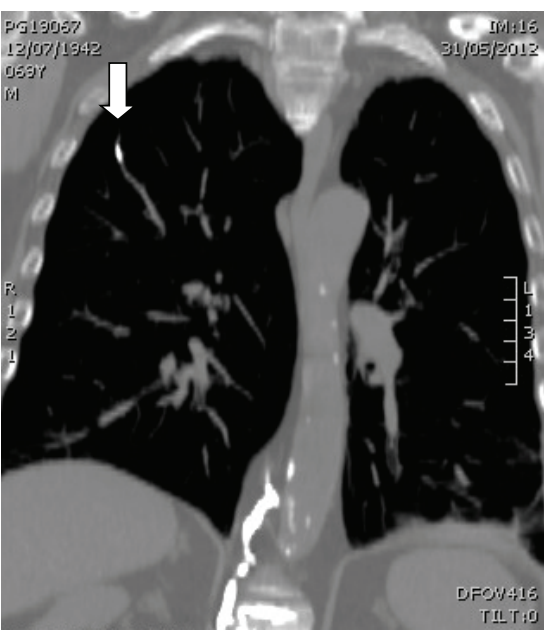

(b)

Figure 2: (a) Cement leakage into the Batson's paravertebral venous system. (b) Pulmonary embolism (arrow: presence of cement in the subsegmentary and segmentary pulmonary arteries of the right superior lobe).

the Batson's paravertebral venous system) and confirmed with chest computed tomography (Figures 2(a) and 2(b)).

Thoracic CT revealed the characteristic appearance of cement leakage at the level of the vertebroplasty in the perivertebral venous system, draining into juxtarenal inferior cava vein, partially obstructed by the same material, and into the azygos system between D9 and L2; the presence of cement in the subsegmentary and segmentary pulmonary arteries of the right superior lobe confirmed a pulmonary microembolism (centimetric areas of shaded ground glass) caused by cement.

The patient was treated with anticoagulants (enoxaparin $4000 \mathrm{IU}$ a day), antibiotics (Amoxicillin $2 \mathrm{~g}$ a day), and corticosteroids (dexamethasone $4 \mathrm{mg}$ a day) and responded favorably.
Prior to discharge on postoperative day 4 , a repeat CT scan showed no substantial change in the distribution of the cement. Therefore, he was discharged home on oral warfarin for chronic anticoagulation (to reduce the risk of thrombosis on the cement remaining in the distal part of the arterial pulmonary tree), and monthly follow up was scheduled.

The followup CT scan showed no further migration of any cement material. Furthermore, no foreign material was identified within the right atrium-internal vena cava junction (Figure 3).

\section{Discussion}

Bone cement has been widely used in orthopaedic procedure and neurosurgery since 1987: PMM cement, a rapidly setting 
TABLE 1: Case reports and series of patients with asymptomatic pulmonary embolism after vertebroplasty, from PubMed database, queries: "complication of vertebroplasty," "bone cement pulmonary embolism" (modified and ampliated from [7]).

\begin{tabular}{|c|c|c|c|}
\hline Authors & $\begin{array}{l}\text { No. of asymptomatic } \\
\text { pulmonary embolism }\end{array}$ & Procedure and indications & Therapy \\
\hline Grados et al., 2000 [10] & $1 / 40(2.5 \%)$ & PVP, osteoporotic fracture & Not reported \\
\hline Bernhard et al., 2003 [11] & 1 & PVP, osteoporotic fracture & Not reported \\
\hline Pleser et al., 2004 [12] & 1 & PVP, osteoporotic fracture & Heparin + warfarin for 6 months \\
\hline Seo et al., 2005 [13] & 1 & PVP, osteoporotic fracture & Operative embolectomy \\
\hline Baumann et al., 2006 [14] & 1 & PVP, osteoporotic fracture & Warfarin for 3 months \\
\hline Freitag et al., 2006 [15] & 1 & PVP, osteoporotic fracture & Warfarin for 6 months \\
\hline MacTaggart et al., 2006 [16] & 1 & PVP, osteoporotic fracture & Not reported \\
\hline Neuwirth et al., 2006 [17] & 1 & PVP, osteoporotic fracture & Not reported \\
\hline Walz et al., 2006 [18] & $1 / 57(2 \%)$ & PVP, osteoporotic fracture & No anticoagulation \\
\hline Quesada and Mutlu, 2006 [19] & 1 & PVP, osteoporotic fracture & Not reported \\
\hline Abdul-Jalil et al., 2007 [20] & 1 & PVP, osteoporotic fracture & Low dose heparin \\
\hline Serra et al., 2007 [21] & $3 / 175(2 \%)$ & PVP, osteoporotic fracture & Not reported \\
\hline Schneider and Plit, 2007 [22] & 1 & PVP, osteoporotic fracture & Not reported \\
\hline Yeo et al., 2009 [23] & $18 / 119(15 \%)$ & PVP, osteoporotic fracture & Not reported \\
\hline Venmans et al., 2008 [24] & $11 / 299(3 \%)$ & PVP, osteoporotic fracture & Not reported \\
\hline Venmans et al., 2010 [25] & $14 / 54(26 \%)$ & PVP, various & Not reported \\
\hline Fornell-Pérez et al., 2010 [26] & 1 & PVP, osteoporotic fracture & Clinical observation \\
\hline Nesnídal et al., 2010 [27] & 1 & PVP, osteoporotic fracture & Clinical observation \\
\hline Dash and Brinster, 2011 [2] & 1 & PVP, osteoporotic fracture & Open heart surgery \\
\hline Luetmer et al., 2011 [28] & $22 / 244(9 \%)$ & PVP, various & Clinical observation \\
\hline Tourtier and Cottez, 2012 [29] & 1 & PVP, osteoporotic fracture & Clinical observation \\
\hline Total & 84 cases & $\begin{array}{l}\text { PVP, osteoporotic } \\
\text { fracture }(100 \%)\end{array}$ & $\begin{array}{c}47 \% \text { not reported } \\
19 \% \text { clinical observation } \\
9 \% \text { warfarin alone } \\
5 \% \text { heparin alone } \\
5 \% \text { heparin + warfarin } \\
5 \% \text { open heart surgery } \\
5 \% \text { embolectomy } \\
5 \% \text { no anticoagulation }\end{array}$ \\
\hline
\end{tabular}

PVP: percutaneous vertebroplasty.

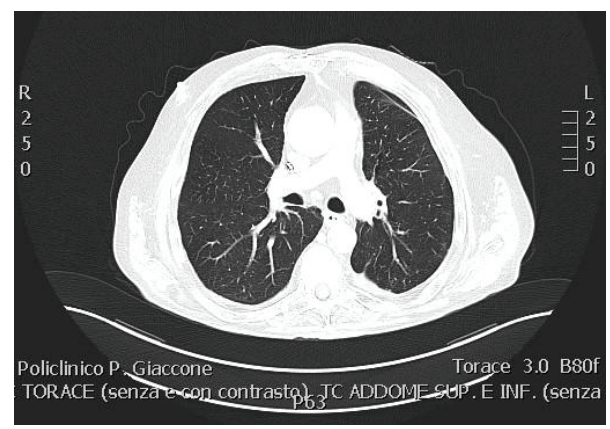

Figure 3: Normal followup CT scan.

bone cement, is injected using a transpedicular or paravertebral approach, under fluoroscopic guidance [1].

Although percutaneous vertebroplasty is a relatively safe, simple, and commonly performed procedure for the management of vertebral compression fractures, it can be associated with fatal complications, such as spinal cord compression resulting in paraplegia, cerebral embolism, penetration of the right ventricle, renal artery embolism, and acute respiratory distress syndrome [2]; minor complications, reported in large series, were rare, local, and temporary and included infection, radicular pain, and spinal cord compression; moreover, most complications involved transitory worsening of pain or chest discomfort, dyspnea, and fever [3]; these symptoms may also lead to cardiovascular collapse and, rarely, to death.

The frequency of local leakage of bone cement is relatively high (about $80-90 \%$ ); moreover, the rate of cement leakage into the perivertebral veins (seen in up to $24 \%$ of vertebral bodies treated) with consequent pulmonary cement embolism varies from 4.6 to $6.8 \%$ (up to $26 \%$ in radiologic studies): the risk is increased with liquid consistency of the PMM and with the treatment of some malignant lesions because of the more frequent cortical destruction of the vertebral body and higher vascularization associated with some malignant tumors; pulmonary embolism is attributable 
to the passage of the PMM into the perivertebral veins and from there into the azygos vein and the inferior vena cava, to end up in the pulmonary vasculature [3-7].

Otherwise, more reviews in the literature published specifically report with no case of cement pulmonary embolism despite the significant numbers of cement leaks into the venous system (Table 1 ).

Patients may remain asymptomatic and develop no known long-term sequelae (when cement emboli are encountered in an asymptomatic patient, they are probably of no clinical significance and have no known long-term sequelae). However, when emboli are discovered incidentally on a conventional chest radiograph, their suggestive appearance is a high-density opacity in a tubular branching pattern, corresponding to pulmonary arterial distribution $[3,8]$.

Some authors reported the use of a preinjection venogram to decrease the incidence of pulmonary embolism, and the injection of sclerosing agents into the vertebral body before vertebroplasty has also been suggested to close venous channels $[2,7]$.

The treatment for symptomatic or central pulmonary cement embolism is surgical embolectomy, or, in selected cases, percutaneous removal, whereas more conservative management with anticoagulants, antibiotics, and corticosteroid is reserved for smaller or peripherally located emboli $[3,9]$ : anticoagulation therapy reduces the risk of thrombus formation on the embolic material but cannot reduce the right ventricle afterload and cannot improve the pulmonary ventilation-perfusion ratio, which is the cause of respiratory failure.

\section{Conclusions}

This case allows us to conclude that the risk of pulmonary embolism of PMM might be underestimated. We confirm the necessity of routine chest radiograph following every vertebroplasty in order to detect pulmonary PMM embolism and thereby prevent serious delayed cardiopulmonary failures.

From our brief literature review, it is clear that no agreement has been reached regarding the therapeutic strategy to be used for pulmonary embolism caused by cement, especially in asymptomatic patients, varying from clinical followup to combined heparin plus warfarin.

Surely, pulmonary embolectomy is a therapeutic tool in critical patients and appears to be a reliable and effective procedure in cases of severe respiratory and cardiac failure due to acrylic cement embolism in the main pulmonary trunks because it is the only treatment that could provide complete recovery from pulmonary and cardiac failure.

Anticoagulants appear to have been effective in preventing pulmonary infarction and improving clinical course although it is imprudent to recommend any therapeutic approach based on a single case.

\section{References}

[1] P. Galibert, H. Deramond, P. Rosat, and D. le Gars, "Preliminary note on the treatment of vertebral angioma by percutaneous acrylic vertebroplasty," Neurochirurgie, vol. 33, no. 2, pp. 166$168,1987$.

[2] A. Dash and D. R. Brinster, "Open heart surgery for removal of polymethylmethacrylate after percutaneous vertebroplasty," Annals of Thoracic Surgery, vol. 91, no. 1, pp. 276-278, 2011.

[3] D. H. Choe, E. M. Marom, K. Ahrar, M. T. Truong, and J. E. Madewell, "Pulmonary embolism of polymethyl methacrylate during percutaneous vertebroplasty and kyphoplasty," The American Journal of Roentgenology, vol. 183, no. 4, pp. 1097-1102, 2004.

[4] C. Duran, M. Sirvanci, M. Aydoğan, E. Ozturk, C. Ozturk, and C. Akman, "Pulmonary cement embolism: a complication of percutaneous vertebroplasty," Acta Radiologica, vol. 48, no. 8, pp. 854-859, 2007.

[5] J. M. Mathis, J. D. Barr, S. M. Belkoff, M. S. Barr, M. E. Jensen, and H. Deramond, "Percutaneous vertebroplasty: a developing standard of care for vertebral compression fractures," The American Journal of Neuroradiology, vol. 22, no. 2, pp. 373-381, 2001.

[6] I. J. Lee, A. L. Choi, M. Y. Yie et al., "CT evaluation of local leakage of bone cement after percutaneous kyphoplasty and vertebroplasty," Acta Radiologica, vol. 51, no. 6, pp. 649-654, 2010.

[7] A. Krueger, C. Bliemel, R. Zettl, and S. Ruchholtz, "Management of pulmonary cement embolism after percutaneous vertebroplasty and kyphoplasty: a systematic review of the literature," The European Spine Journal, vol. 18, no. 9, pp. 1257-1265, 2009.

[8] B. Padovani, O. Kasriel, P. Brunner, and P. Peretti-Viton, "Pulmonary embolism caused by acrylic cement: a rare complication of percutaneous vertebroplasty," The American Journal of Neuroradiology, vol. 20, no. 3, pp. 375-377, 1999.

[9] P. Tozzi, Y. Abdelmoumene, A. F. Corno, P. A. Gersbach, H. M. Hoogewoud, and L. K. von Segesser, "Management of pulmonary embolism during acrylic vertebroplasty," Annals of Thoracic Surgery, vol. 74, no. 5, pp. 1706-1708, 2002.

[10] F. Grados, C. Depriester, G. Cayrolle, N. Hardy, H. Deramond, and P. Fardellone, "Long-term observations of vertebral osteoporotic fractures treated by percutaneous vertebroplasty," Rheumatology, vol. 39, no. 12, pp. 1410-1414, 2000.

[11] J. Bernhard, P. F. Heini, and P. M. Villiger, "Asymptomatic diffuse pulmonary embolism caused by acrylic cement: an unusual complication of percutaneous vertebroplasty [4]," Annals of the Rheumatic Diseases, vol. 62, no. 1, pp. 85-86, 2003.

[12] M. Pleser, R. Roth, O. Wörsdörfer, and C. Manke, "Pulmonary embolism caused by PMMA in percutaneous vertebroplasty. Case report and review of the literature," Unfallchirurg, vol. 107, no. 9, pp. 807-811, 2004.

[13] J. S. Seo, Y. J. Kim, B. W. Choi, T. H. Kim, and K. O. Choe, "MDCT of pulmonary embolism after percutaneous vertebroplasty," The American Journal of Roentgenology, vol. 184, no. 4, pp. 1364-1365, 2005.

[14] A. Baumann, J. Tauss, G. Baumann, M. Tomka, M. Hessinger, and K. Tiesenhausen, "Cement embolization into the vena cava and pulmonal arteries after vertebroplasty: interdisciplinary management," The European Journal of Vascular and Endovascular Surgery, vol. 31, no. 5, pp. 558-561, 2006.

[15] M. Freitag, A. Gottschalk, M. Schuster, W. Wenk, L. Wiesner, and T. G. Standl, "Pulmonary embolism caused by polymethylmethacrylate during percutaneous vertebroplasty in orthopaedic surgery," Acta Anaesthesiologica Scandinavica, vol. 50, no. 2, pp. 248-251, 2006. 
[16] J. N. MacTaggart, I. I. Pipinos, J. M. Johanning, and T. G. Lynch, "Acrylic cement pulmonary embolus masquerading as an embolized central venous catheter fragment," Journal of Vascular Surgery, vol. 43, no. 1, pp. 180-183, 2006.

[17] J. Neuwirth, J. C. Weber, and B. Kohler, "Pulmonary cement embolism after vertebroplasty in multiple osteoporotic vertebral fractures," Deutsche Medizinische Wochenschrift, vol. 131, pp. 2275-2276, 2006.

[18] M. Walz, E. Esmer, and B. Kolbow, "CT-based analysis of cement distribution in unipedicular vertebroplasty," Unfallchirurg, vol. 109, no. 11, pp. 932-939, 2006.

[19] N. Quesada and G. M. Mutlu, "Pulmonary embolization of acrylic cement during vertebroplasty," Circulation, vol. 113, no. 8, pp. e295-e296, 2006.

[20] Y. Abdul-Jalil, J. Bartels, O. Alberti, and R. Becker, "Delayed presentation of pulmonary polymethylmethacrylate emboli after percutaneous vertebroplasty," Spine, vol. 32, no. 20, pp. E589-E593, 2007.

[21] L. Serra, F. M.. Kermani, K. Panagiotopoulos, V. de Rosa, and L. Vizioli, "Vertebroplasty in the treatment of osteoporotic vertebral fractures: results and functional outcome in a series of 175 consecutive patients," Minimally Invasive Neurosurgery, vol. 50, no. 1, pp. 12-17, 2007.

[22] L. Schneider and M. Plit, "Pulmonary embolization of acrylic cement during percutaneous vertebroplasty [3]," Internal Medicine Journal, vol. 37, no. 6, pp. 423-425, 2007.

[23] J. K. Yeo, W. L. Joon, W. P. Kun et al., "Pulmonary cement embolism after percutaneous vertebroplasty in osteoporotic vertebral compression fractures: incidence, characteristics, and risk factors," Radiology, vol. 251, no. 1, pp. 250-259, 2009.

[24] A. Venmans, P. N. M. Lohle, W. J. van Rooij, H. J. J. Verhaar, and W. P. T. M. Mali, "Frequency and outcome of pulmonary polymethylmethacrylate embolism during percutaneous vertebroplasty," The American Journal of Neuroradiology, vol. 29, no. 10, pp. 1983-1985, 2008.

[25] A. Venmans, C. A. H. Klazen, P. N. M. Lohle et al., "Percutaneous vertebroplasty and pulmonary cement embolism: results from VERTOS II," The American Journal of Neuroradiology, vol. 31, no. 8, pp. 1451-1453, 2010.

[26] R. Fornell-Pérez, J. M. Santana-Montesdeoca, and P. JunqueraRionda, "Multiple pulmonary embolisms caused by acrylic cement after vertebroplasty," Archivos de Bronconeumologia, vol. 46, no. 9, pp. 493-494, 2010.

[27] P. Nesnídal, J. Stulík, and P. Sebesta, "Pulmonary polymethylmetacrylate embolism: a rare complication of percutaneous vertebroplasty," Acta Chirurgiae Orthopaedicae et Traumatologiae Cechoslovaca, vol. 77, no. 4, pp. 337-340, 2010.

[28] M. T. Luetmer, B. J. Bartholmai, A. E. Rad, and D. F. Kallmes, "Asymptomatic and unrecognized cement pulmonary embolism commonly occurs with vertebroplasty," The American Journal of Neuroradiology, vol. 32, no. 4, pp. 654-657, 2011.

[29] J. P. Tourtier and S. Cottez, "Images in clinical medicine. Pulmonary cement embolism after vertebroplasty," The New England Journal of Medicine, vol. 366, no. 3, article 258, 2012. 


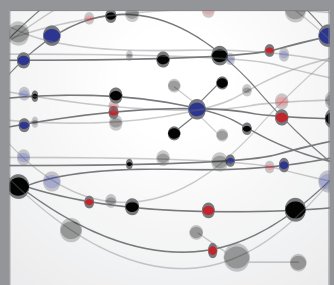

The Scientific World Journal
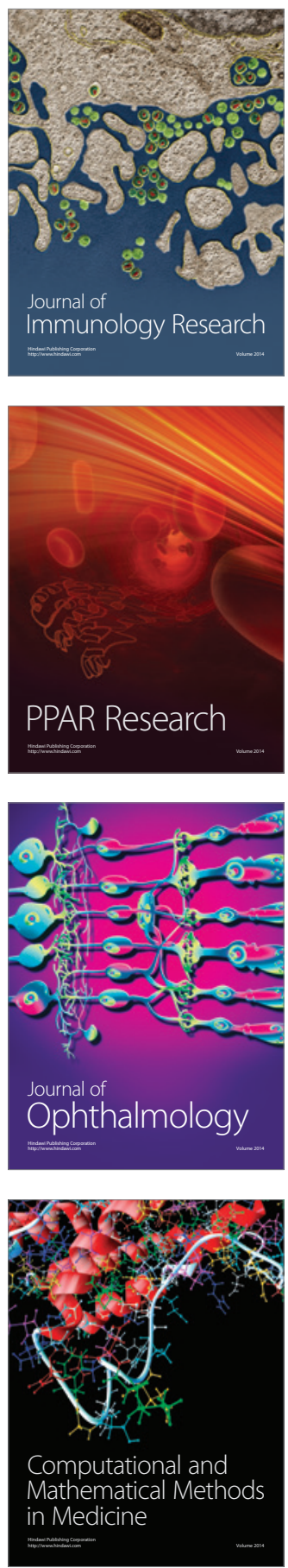

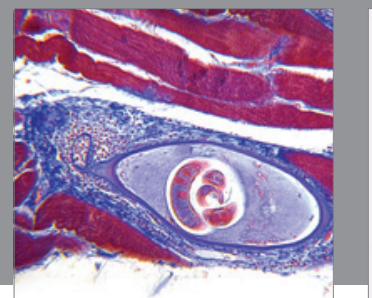

Gastroenterology

Research and Practice
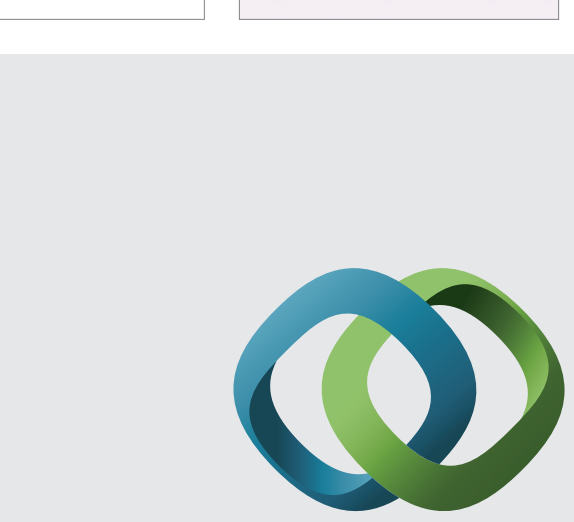

\section{Hindawi}

Submit your manuscripts at

http://www.hindawi.com
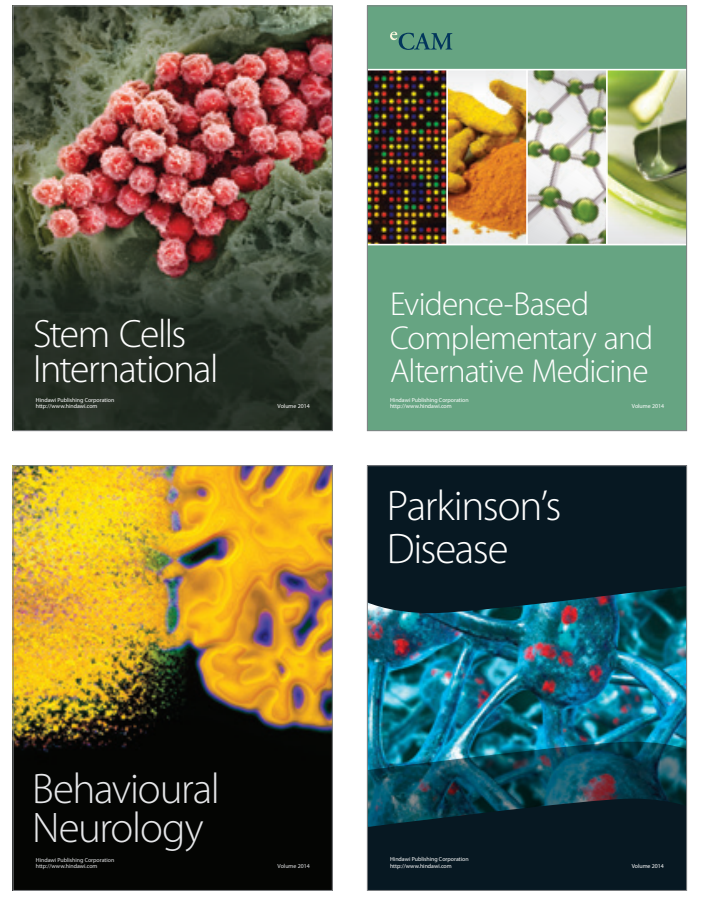
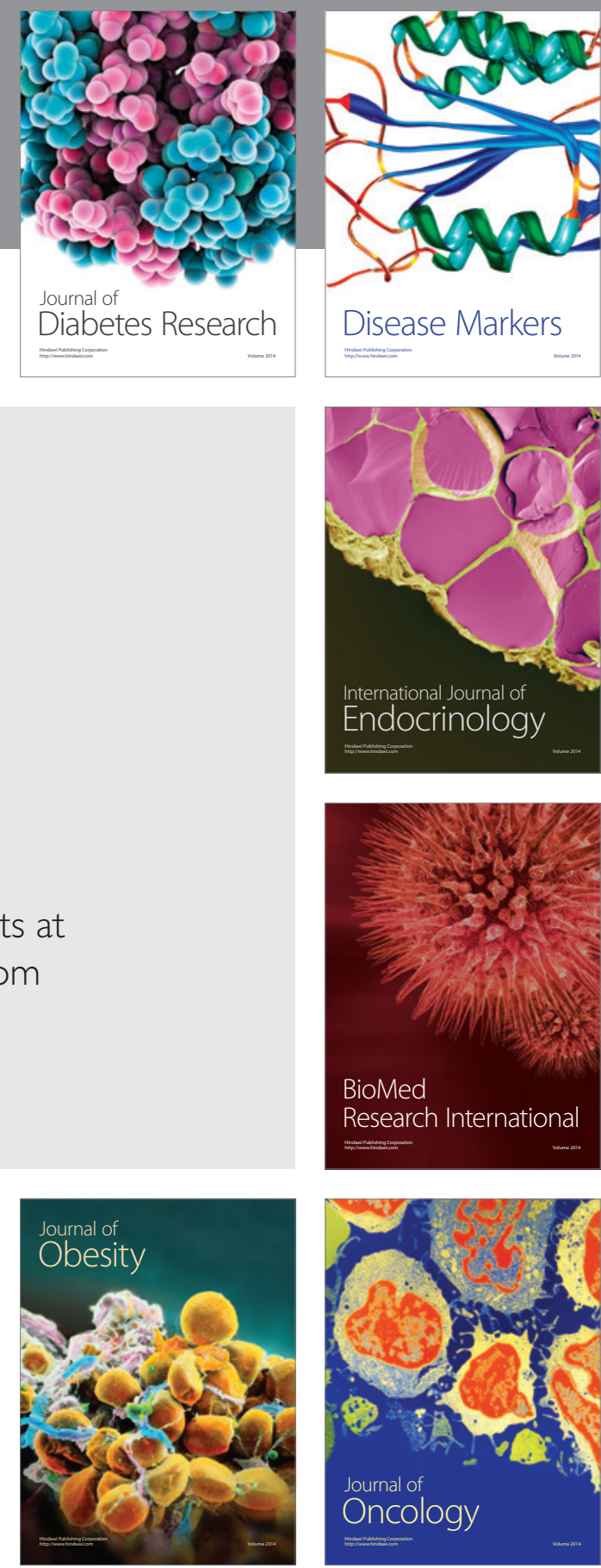

Disease Markers
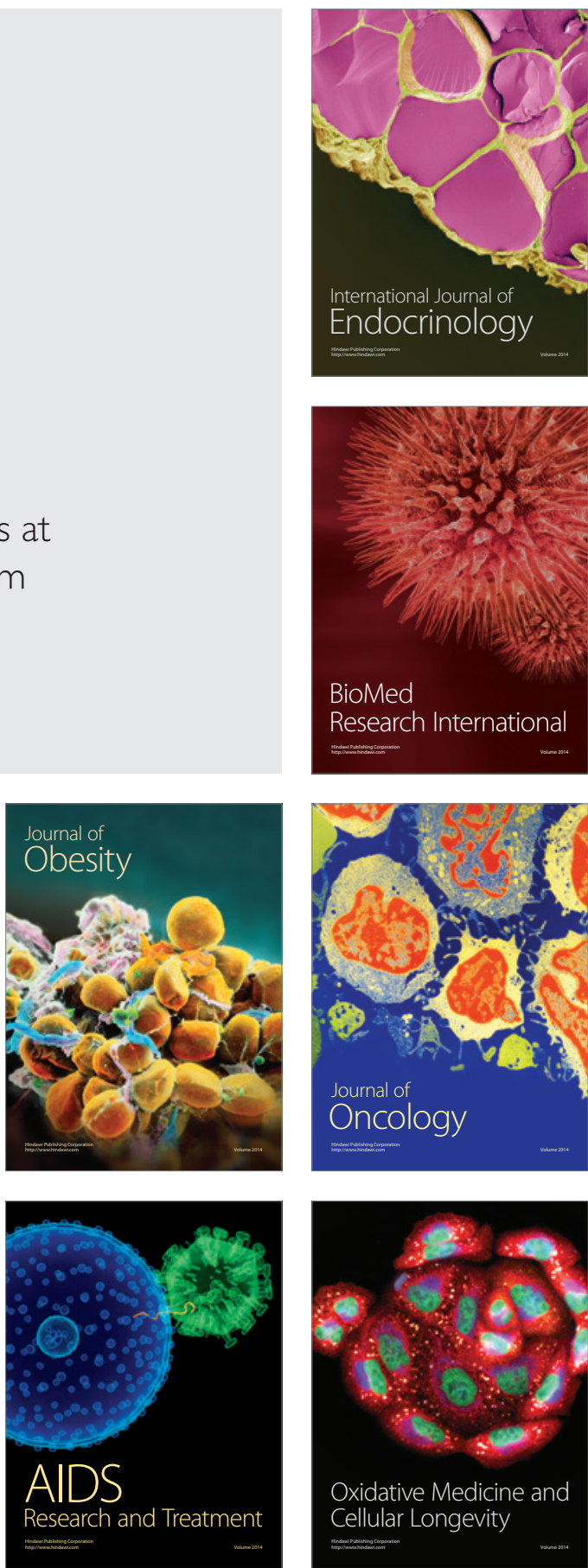